\title{
Management of Malignant Pericardial Effusion
}

\author{
MARY PETROFSKY, MS, RN, ACNP, AOCNP ${ }^{\circledR}$
}

From Stanford Hospital and Clinics, Stanford, California

Author's disclosures of potential conflicts of interest are found at the end of this article.

Correspondence to: Mary Petrofsky, MS, RN, ACNP, AOCNP®, Stanford Hospital and Clinics, Hematology/Oncology Department, 300 Pasteur Drive, Room H0105, Mail Code 5221, Stanford, CA 94305-5221. E-mail: m_petrof@yahoo.com

(c) 2014 Harborside Press ${ }^{\circledR}$

\section{CASE STUDY}

In early 2010, Mrs. Y., a 58-year-old Japanese woman, underwent a routine mammogram that revealed left focal asymmetry. A biopsy demonstrated invasive ductal carcinoma, and she was referred to surgery. She underwent a lumpectomy and left axilla sentinel lymph node biopsy. Pathology confirmed an invasive ductal adenocarcinoma, moderately differentiated, $1.2 \mathrm{~cm}$, estrogen receptor (ER)/progesterone receptor (PR) negative, and HER2/neu negative with negative surgical margins. Three left axillary sentinel lymph nodes showed no evidence of disease.

Mrs. Y. was diagnosed with stage I T1cNOMx breast cancer. Her oncologist estimated that she had a 25\% 10-year risk of relapse and a $13 \%$ 10-year risk of mortality, with an estimated 35\% mortality benefit conferred by adjuvant therapy. Although it was recognized that triplenegative breast cancer confers a worse prognosis (Foulkes, Smith, \& Reis-Filho, 2010), no available prognostic calculators considered hormone receptor status; the oncologist's projections were overly optimistic. In a recent retrospective study in triple-negative breast cancer patients, Hernandez-Aya et al. (2011) found a 5-year mortality rate of $16 \%$ for T1NO patients and a 5 -year relapse of $26 \%$ in these patients, similar to what Mrs. Y.'s oncologist had estimated for 10 years.

The oncologist recommended adjuvant therapy, and Mrs. Y. received four cycles of adjuvant docetaxel and cyclophosphamide followed by radiation therapy to the tumor bed and left breast. Her treatment followed the course recommended by the National Comprehensive Cancer Network Guidelines at that time (Carlson et al., 2009). She completed therapy in October 2010 without having experienced any dose reductions, delays, or complications.

Mrs. Y. continued to show no evidence of disease until early 2013, when she developed left neck and arm swelling. Computed tomography (CT) scan of the neck and thorax revealed a left supraclavicular mass compressing the left internal jugular and subclavian veins and enlarged cervical lymph nodes. A biopsy of the supraclavicular mass confirmed metastatic breast cancer. CT scan of the abdomen and pelvis showed no other sites of disease. She was treated with involved-field irradiation (16 Gy) to the sites of tumor recurrence and then was lost to follow-up. 
Six months following completion of irradiation, Mrs. Y. presented to the emergency department (ED) with dyspnea. On review of systems, she reported a 3-month history of a progressive cough and a 3-week history of hoarseness with progressive shortness of breath (SOB) and difficulty speaking. Upon physical examination, her voice was hoarse, breath sounds were clear to auscultation, and there were palpable left supraclavicular nodes. She did not have muffled heart sounds, elevated jugular venous pressure (JVP), or pulsus paradoxus. In the ED, her vital signs were blood pressure (BP) 129/85, pulse 89, oxygen saturation 98\%, and respirations 16 . An electrocardiogram (ECG) revealed sinus rhythm with borderline T-wave abnormalities in diffuse leads and a heart rate of 94. Her troponin I level was zero. A CT angiogram revealed a moderate-sized pericardial effusion (Figure 1) and supraclavicular and mediastinal lymphadenopathy with no evidence of a pulmonary embolus. Ultrasound confirmed a moderate pericardial effusion with no evidence of tamponade.

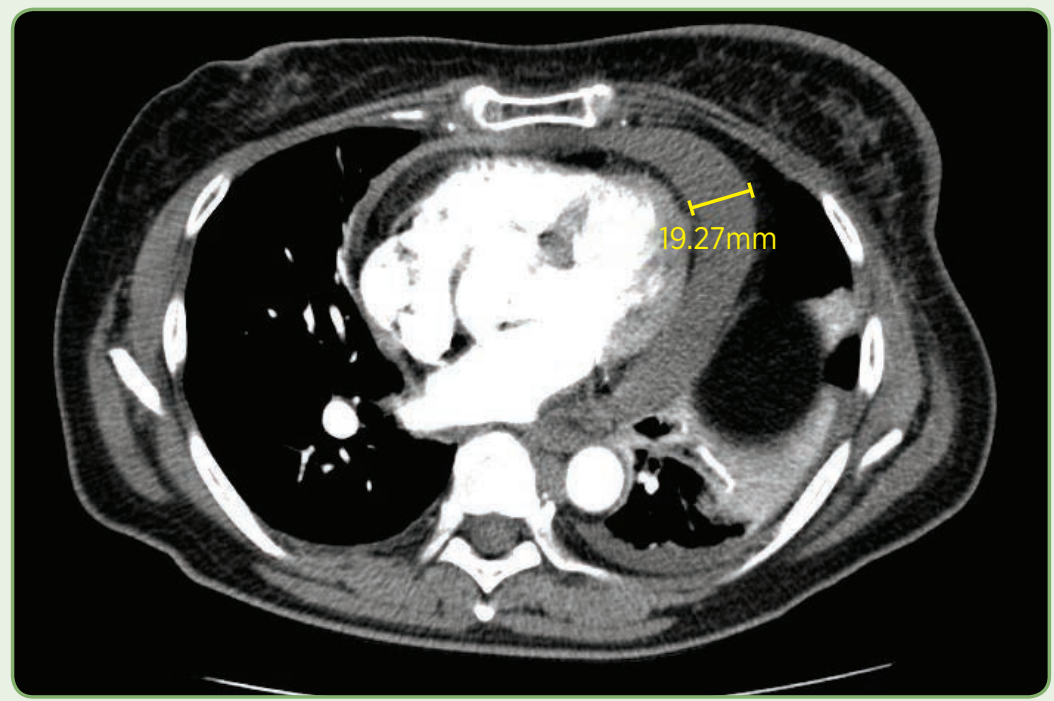

Figure 1. CT pulmonary embolus study showing pericardial effusion measuring $19.27 \mathrm{~mm}$ in this plane.
Overnight, Mrs. Y.'s shortness of breath remained stable but her blood pressure dropped to 70/49, which improved to $80 / 62$ in response to a normal saline bolus. An ECG revealed sinus rhythm with partial resolution of the $\mathrm{T}$ wave abnormalities and a heart rate of 65 . Systolic blood pressure remained below 90 for several hours despite fluid boluses; by morning her blood pressure had improved to 93/63. Echocardiography (echo) revealed a moderate-sized circumferential pericardial effusion with mild diastolic right atrium/right ventricle collapse, a dilated inferior vena cava, and mild mitral valve inflow variation with respiration, consistent with mild hemodynamic compromise. Left ventricle size and systolic function were normal.

Based on the echo findings, newly elevated JVP, and ongoing hypotension, Mrs. Y. was diagnosed with cardiac tamponade and suspected malignant pericardial effusion. Cardiology performed a diagnostic and therapeutic echo-guided pericardiocentesis and removed $260 \mathrm{~mL}$ of a bloody turbid fluid. A drain was left in, but it removed only $10 \mathrm{~mL}$ of fluid overnight and was removed the next day. Mrs. Y. had almost immediate relief of her dyspnea, and by day 3 she reported that she felt "a hundred times better" than she had at admission. She was discharged later that day after repeat echo showed a stable small pericardial effusion. Cytology of the pericardial fluid ultimately revealed metastatic adenocarcinoma consistent with the original breast cancer diagnosis.

he pericardium surrounds the heart and the great blood vessels and is composed of a thin visceral membrane, a fibrous parietal membrane, and the pericardial space between the membranes, which normally contains less than 50 $\mathrm{mL}$ of an ultrafiltrate of plasma known as pericardial fluid (Hoit, 2011; Braunwald, 2012).
The parietal membrane is composed primarily of collagen and elastin fibers, which gives the membrane some elasticity (Braunwald, 2012). As a result of this elasticity, the normal pericardium has a nonlinear pressure-volume curve. Small pericardial fluid volume changes do not generally result in any change in pericardial pressure, but a large sudden increase in peri- 
cardial volume can cause a steep change in pericardial pressure, leading to tamponade (Imazio \& Adler, 2013).

With a slowly enlarging pericardial effusion, the pericardial membranes stretch to accommodate the growing fluid volume without any significant change in the pericardial pressure until the limit of pericardial membrane stretch is reached. When pericardial fluid volume increases beyond the limit of membrane stretch, cardiac tamponade results (Imazio \& Adler, 2013). Surprisingly, although the pericardium has many normal functions (Table 1), there are no significant consequences if the pericardium is removed or congenitally absent (Hoit, 2011; Braunwald, 2012).

\section{ETIOLOGY OF PERICARDIAL EFFUSIONS}

Pericardial effusions can be idiopathic, infectious (most commonly viral), cardiac, autoimmune, medication-induced, radiation-induced, traumatic, metabolic, malignant, or the result of other causes (Imazio \& Adler, 2013). The most common cause in cancer patients is a malignant effusion from lung or breast cancer (Lestuzzi, 2010; Pawlak-Cieślik et al., 2012), but nonmalignant etiologies (thoracic radiation, infection, autoimmune process, and medication) and other cancers (other solid tumors, hematologic malignancies, Hodgkin lymphoma, and non-Hodgkin lymphoma) can also cause effusions (Maisch, Ristić, \& Pankuweit, 2010). Chemotherapeutic agents that can cause pericardial effusion include cyclophosphamide, cytarabine, dasatinib (Sprycel), doxorubicin, gemcitabine, and other cardiotoxic agents (Svoboda, 2010).

\section{SYMPTOMS AND EXAM FINDINGS}

Effusions that develop quickly are the most likely to cause symptoms and physical exam findings (Seferović et al., 2013; Burazor, Imazio, Markel, \& Adler, 2013). Dyspnea is the most common symptom in malignant pericardial effusion (Svoboda, 2010). Other symptoms include pleuritic chest discomfort, cough, fatigue, hoarseness from recurrent laryngeal nerve compression, and hiccups from phrenic nerve compression, with syncope being particularly concerning for tamponade (Borlaug, DeCamp, \& Gangadharan, 2013; Refaat \& Katz, 2011).
Pericardial effusions can be difficult to diagnose because clinical findings have poor sensitivity; tachycardia may be the only sign (PawlakCieślik et al., 2012). The classic physical exam findings that are concerning for tamponade are collectively referred to as Beck's triad: hypotension (often with a narrow pulse pressure), tachycardia, and muffled heart sounds. Beck's triad was initially described for acute tamponade, which develops over minutes to hours; it is rarely seen in cancer patients with malignant pericardial effusions, who tend to develop subacute tamponade over days to weeks (Argulian, Herzog, Halpern, \& Messerlin, 2012; Borlaug et al., 2013; Imazio \& Adler, 2013). Other signs of tamponade include elevated JVP and pulsus paradoxus (Refaat \& Katz, 2011). Pulsus paradoxus above $10 \mathrm{~mm} \mathrm{Hg}$ has been reported to be the most sensitive physical finding for tamponade but still only has a sensitivity of $82 \%$, followed by tachycardia and elevated JVP, with sensitivities of $77 \%$ and $76 \%$, respectively (Sherbino, 2009).

\section{DIAGNOSTIC WORKUP}

Given that dyspnea is the most common symptom, a chest x-ray is often the first study obtained. An enlarged cardiac silhouette with clear lungs (the "water bottle sign," as shown in Figure 2) is the classic finding in pericardial effusion, and concomitant pleural effusion is common in malignant pericardial effusions (Hoit, 2013a). The patient's ECG may be normal, or it can demonstrate low QRS voltage, nonspecific ST- or T-wave changes, or electromechanical dissociation (agonal phase; Svoboda, 2010). Low QRS voltage is indicative of cardiac tamponade, but its absence does not rule

\section{Table 1. Functions of the Pericardium}

- Preventing sudden dilation of the cardiac chambers

- Preventing kinking of the great vessels

- Acting as a shock absorber for deceleration forces

- Limiting cardiac distention

- Influencing ventricular filling

- Coupling pressure and volume on one side of the heart to pressure and volume on the other side

- Minimizing friction between the heart and surrounding structures

- Acting as a mechanical barrier to infection

Note. Information from Hoit (2011), Braunwald (2012), Mallemat \& Tewelde (2013). 


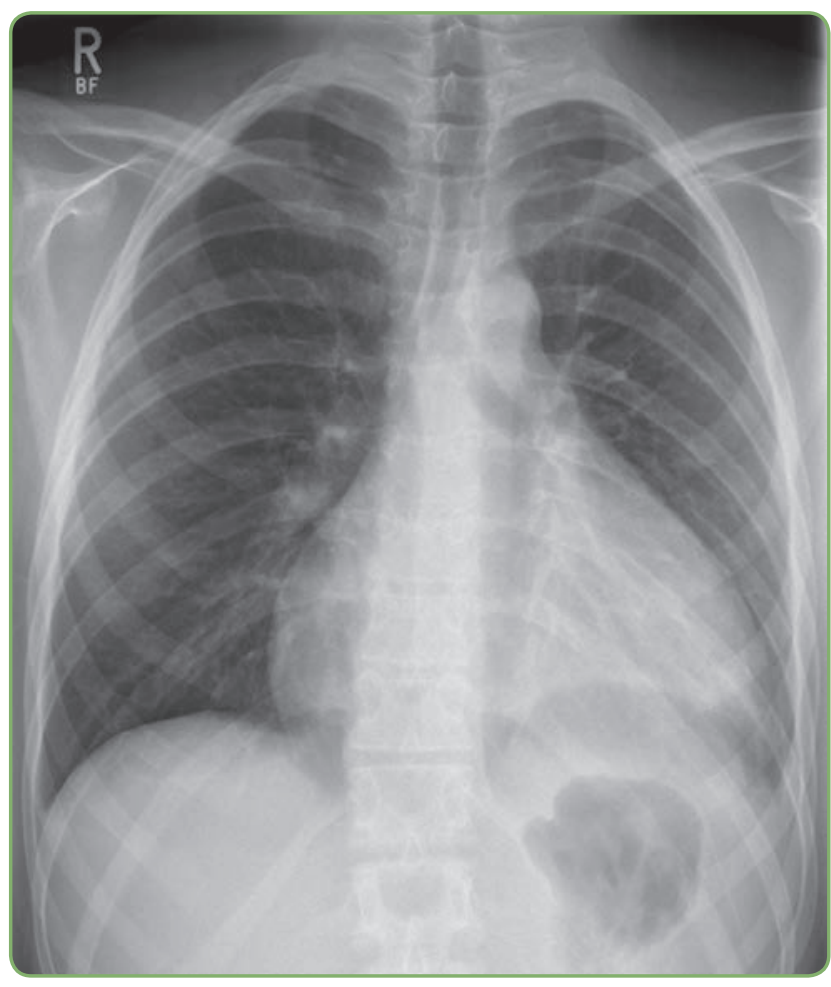

Figure 2. Water bottle sign on chest $x$-ray (Hellerhoff, 2010).

out tamponade (Seferović et al., 2013). Low QRS voltage is most commonly associated with tamponade caused by a malignant pericardial effusion and usually resolves within a week of pericardiocentesis (Oliver et al., 2002). Elevated troponin I and creatine kinase myoglobin levels are commonly seen but appear to have no prognostic implication (Imazio et al., 2013).

Echo is the diagnostic standard, as it is the most useful imaging study for determining the presence, size, location, and hemodynamic effect of a pericardial effusion (Hoit, 2011). Although a CT of the thorax is generally not a good modality for determining the severity of an effusion, both $\mathrm{CT}$ and magnetic resonance imaging (MRI) may be superior to echo for determining the amount and distribution of pericardial fluid and whether

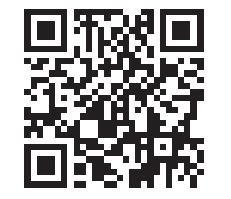

Use your smartphone to access the Guidelines on the Diagnosis and Management of Pericardial Diseases Executive Summary from the European Society of Cardiology. an effusion is hemorrhagic or loculated (Bogaert \& Francone, 2013). Cardiac chamber collapse on echo typically occurs before clinical hemodynamic failure (Mallemat \& Tewelde, 2013). Echo findings consistent with cardiac tamponade include collapse of the right atrium at end diastole and the right ventricle in early diastole, reciprocal changes in left and right ventricular volumes with respiration, increased respiratory variation of mitral and tricuspid valve inflow velocities, and inferior vena cava (IVC) dilatation with less than a $50 \%$ reduction in IVC diameter during inspiration (Hoit, 2013b). See Table 2 for a list of key elements in diagnosing malignant pericardial effusion.

\section{INITIAL MANAGEMENT}

In 2004, the Task Force on the Diagnosis and Management of Pericardial Diseases of the European Society of Cardiology published guidelines for the management of pericardial effusion (Maisch et al., 2004). Although there are many articles that specifically address pericardial effusions in patients with cancer, there have been no randomized controlled trials or prospective intervention trials (Burazor et al., 2013). Treatment of pericardial effusion secondary to malignant disease requires consideration of the patient's prognosis from the underlying malignancy, the availability of local expertise, and the cardiovascular and medical status of the patient (Imazio \& Adler, 2013). Stable patients without evidence of tamponade can be managed with careful monitoring, serial echo studies, avoidance of volume depletion, and therapy aimed at the underlying cause of the pericardial effusion (Borlaug et al., 2013), regardless of effusion size (Mallemat \& Tewelde, 2013).

Patients with evidence of tamponade who are hypovolemic should be given volume resuscitation if systolic BP is below $100 \mathrm{mmHg}$ (SagristàSauleda, Angel, Sambola, \& Permanyer-Miralda, 2008). In tamponade, there is a significant increase in the pericardial pressure, and the central venous pressure must be kept higher than the pericardial pressure in order for the heart to fill. If volume resuscitation results in hemodynamic improvement, such patients may be observed closely without urgent need for pericardiocentesis (Hoit, 2013b). In patients with cancer, pericardiocentesis is indicated for symptomatic cardiac tamponade and for 
high suspicion of tuberculous or infectious etiology (Maisch et al., 2013; Sagristà-Sauleda et al., 2011).

In general, pericardial effusion drainage should be considered if the echo demonstrates chamber collapse and the patient is symptomatic; drainage is not necessarily indicated for echocardiographic right atrial collapse in an asymptomatic patient (Hoit, 2011; Maisch, Ristić, Seferovic, \& Tsang, 2011). Furthermore, pericardiocentesis is associated with risk and will not always resolve symptoms (Mallemat \& Tewelde, 2013). Major complications of pericardiocentesis in a large study $(1,127$ procedures) occurred in $1.2 \%$ of echo-guided cases and included heart chamber laceration requiring surgery, pneumothorax, ventricular tachycardia, and bacteremia (Tsang et al., 2002). Minor complications requiring monitoring but no intervention occurred in $3.5 \%$ of echo-guided cases and included transient heart chamber entrance and small pneumothorax (Tsang et al., 2002).

If pericardiocentesis is required, different approaches can be used (Table 3). Pericardiocentesis may be followed by catheter placement for ongoing fluid removal until the rate of fluid return is less than 20 to $30 \mathrm{~mL}$ over 24 hours (Imazio, Spodick, Brucato, Tinchero, \& Adler, 2010). The risk of recurrence of pericardial effusion is significantly reduced when pericardiocentesis is followed by extended catheter drainage, with 6-month recurrence rates of $14 \%$ vs. $27 \%$ with and without extended drainage (Tsang et al., 2002). However, it is important to note that only $33 \%$ of the sample in this study had a malignant pericardial effusion, and malignancy was independently correlated with increased risk of effusion recurrence (Tsang et al., 2002). Repeat echo should be performed after pericardiocentesis to confirm adequate fluid removal and to detect early recurrent fluid accumulation (Cheitlin et al., 2003).

The most helpful pericardial fluid studies are cytology, Gram stain, and bacterial/fungal cultures, although negative cytology is not sufficient to exclude malignancy (Maisch et al., 2011). In immunocompromised patients, polymerase chain reaction studies for viruses can be helpful, such as cytomegalovirus in transplant patients (Maisch et al., 2011). Protein, lactate dehydrogenase, glucose, and cell count have not been shown to be diagnostically helpful because they do not reliably distin-

\section{Table 2. Diagnosing Malignant Pericardial Effusion}

\section{Common presenting symptoms}

- Dyspnea (the most common symptom)

- Pleuritic chest discomfort

- Cough

- Fatigue

- Hoarseness

- Hiccups

- Syncope (concerning for tamponade)

- Symptoms are most commonly associated with rapidly accumulating effusions

\section{Physical exam findings}

- Normal physical exam is most common unless cardiac tamponade is present

- Tachycardia is the most common finding and can be present without tamponade

- Hypotension

- Muffled heart sounds

- Elevated JVP

- Pulsus paradoxus

\section{Diagnostic workup}

- Chest x-ray to rule out other causes of dyspnea: Look for enlarged cardiac silhouette

-12-lead ECG: Normal results are common but can show sinus tachycardia, diminished QRS amplitude, nonspecific ST- or T-wave changes, and/or electrical alternans

- Echocardiography: Confirms presence and size of pericardial effusion; may show cardiac chamber collapse; indications of cardiac tamponade include collapse of the right atrium at end diastole and right ventricle in early diastole, reciprocal changes in left and right ventricular volumes with respiration, and IVC dilatation with less than a $50 \%$ reduction in IVC diameter during inspiration

Note. JVP = jugular venous pressure; ECG = electrocardiogram; IVC = inferior vena cava. Information from Borlaug et al. (2013), Burazor et al. (2013), Hoit (2013b), Refaat \& Katz (2011), Svoboda (2010).

guish malignant from benign pericardial effusions (Karatolios, Pankuweit, \& Maisch, 2013).

There is significant controversy regarding the best time for consideration of surgical rather than percutaneous decompression of pericardial effusions in patients with malignancy. It is well documented that pericardial effusions have a higher risk of recurrence after pericardiocentesis compared with surgical interventions, with recurrence rates as high as $90 \%$ in patients with malignancy (Refaat \& Katz, 2011). Although surgical interventions result in increased discomfort and morbidity compared with pericardiocentesis (Svoboda, 2010), for a patient who experiences multiple symptomatic recurrences of a malignant pericardial effusion, a surgical decompression may result in overall im- 
provement in quality of life with more time outside the hospital despite the initial increase in morbidity. A variety of surgical options exist, some of which can create a pericardial window to allow ongoing drainage to the pleural or peritoneal space (Table 3 ).

\section{PREVENTION OF RECURRENCE}

The guidelines of the European Society of Cardiology include the following options to prevent recurrence of malignant pericardial effusions: systemic antineoplastic treatment, intrapericardial instillation of sclerosing or cytotoxic agents, percutaneous balloon pericardiotomy, surgical subxiphoid pericardiotomy or pleuropericardiotomy, and radiation therapy (Maisch et al., 2004). Although anti-inflammatory medications have been shown to be very useful in inflammatory pericardial effusions, they have little utility in malignant effusions (Imazio \& Adler, 2013). The standard recommendation is systemic chemo- therapy to control the cause of the malignant effusion (Lestuzzi, 2010; Maisch et al., 2004; Refaat \& Katz, 2011). Instillation of sclerosing agents has been shown to have little impact on effusion reaccumulation or survival (Kunitoh et al., 2009). Percutaneous balloon cardiotomy is less invasive than surgical interventions and has a good success rate (Maisch et al., 2011). The various surgical options outlined in Table 3 have a lower rate of effusion recurrence than do percutaneous interventions, but they incur higher morbidity. Radiation therapy was used historically to control malignant pericardial disease (Cham, Freiman, Carstens, \& $\mathrm{Chu}, 1975)$, but it is no longer favored, as it can also cause pericardial effusions (Svoboda, 2010).

Intrapericardial instillation of cisplatin is favored in some centers, with a reported response rate of $93 \%$, a response duration of 3 months, and greater efficacy in lung cancer vs. breast cancer (Maisch et al., 2010). Intrapericardial instillation

\section{Table 3. Techniques for the Management of Malignant Pericardial Effusion}

\section{Noninvasive}

- Monitoring with serial echocardiograms and therapy aimed at the malignancy is reasonable in stable patients without evidence of tamponade.

\section{Pericardiocentesis}

- Echocardiography should be used to determine the optimal approach. Using one of the following approaches, the needle is introduced and is then advanced into the pericardial space for removal of pericardial fluid.

- Subcostal (subxiphoid) approach: A needle is introduced substernally inferior to the left xiphocostal angle and angled toward the left shoulder.

- Parasternal approach (most common): A needle is inserted over the superior border of the 5th or 6th rib adjacent to the left sternal margin.

- Apical approach: A needle is introduced over the superior border of the rib at least $5 \mathrm{~cm}$ lateral to the parasternal approach within the 5 th, 6 th, or 7 th intercostal space and advanced toward the right shoulder.

- If an angiocatheter is used to initiate the pericardiocentesis, a guide wire can then be advanced through the angiocatheter for placement of a pigtail catheter, which remains in place until the 24-hr drainage is less than 20-30 mL.

\section{Percutaneous balloon cardiotomy}

- After pericardiocentesis, a balloon catheter is inserted into the pericardium, and multiple inflations of the balloon create a pericardial window.

- This procedure is less invasive and less risky than the surgical interventions.

\section{Surgical options}

- Subxiphoid pericardiotomy: A 4-6 cm subxiphoid incision is made through the rectus abdominis muscles. A 2-4 cm piece of pericardium is then removed, after which the pericardial sac is drained with a silicone tube.

- Subxiphoid drainage with creation of a pericardio-peritoneal window: Starts as above. Sections of the inferior pericardium and the diaphragm are removed and the opened edges of the pericardium and the diaphragm are sutured to create an open "window" between the pericardium and the peritoneal space.

- Anterolateral thoracotomy with creation of a pleuropericardial window: The chest is opened between the 4th and 5th intercostal spaces and a $2-5 \mathrm{~cm}$ piece of pericardium is removed.

- Video-assisted thoracoscopic pericardiectomy with creation of a pleuropericardial window: Several small thoracic incisions are made in the intercostal spaces and trocars are introduced for passage of the endoscopic camera and surgical instruments. The pleural cavity and lung are examined first. A large pleuropericardial window is then created.

Note. Information from Borlaug et al. (2013), Heffner (2013), Gumrukcuoglu et al. (2011), Maisch et al. (2011), Svoboda (2010), Uramoto \& Hanagiri (2010). 
of thiotepa has been used in breast cancer with good effect (Burazor et al., 2013). Although a retrospective review showed significant improvement in outcomes for patients treated with both intrapericardial and systemic chemotherapy (Lestuzzi et al., 2011), the use of such practices has not been widely adopted due to the potential for pain caused by introduction of the agents and concern for later development of constrictive pericarditis (Borlaug et al., 2013).

\section{PROGNOSTIC IMPLICATIONS}

Development of a symptomatic pericardial effusion in a patient with a malignancy confers a poor prognosis, with a median survival time of 2 to 5 months from the time of detection (Dequanter, Lothaire, Berghmans, \& Sculier, 2008). Prognosis may be slightly better in the subset of patients with negative cytology (Neragi-Miandoab et al., 2008), hematologic rather than solid malignancies (Svoboda, 2010), and breast rather than lung or other solid tumors (Kim et al., 2010). Leukemic pericardial effusions have been shown to be relatively frequent (20\%) but generally asymptomatic and small, with a large retrospective review showing that only $3 \%$ of such pericardial effusions required intervention (Sampat et al., 2010).

\section{CASE DISCUSSION AND UPDATE}

After the pericardiocentesis, Mrs. Y. began systemic chemotherapy as recommended. She had no further issues related to the pericardial effusion in the 5 months after the pericardiocentesis, although her metastatic breast cancer continued to progress. Repeat CT imaging showed only a small residual effusion (Figure 3).

Mrs. Y.'s case is somewhat unusual in that she became symptomatic with a relatively small effusion. In slowly accumulating effusions (the typical pattern in malignancy), patients are rarely symptomatic with an effusion size less than 500 $\mathrm{mL}$ (Schoen \& Mitchell, 2010) and may remain asymptomatic until $2,000 \mathrm{~mL}$ or more has accumulated (Hoit, 2013a). However, symptoms are a result not only of effusion size, but also of the rate of fluid accumulation relative to pericardial stretch and how effectively the heart compensates for the reduced heart chamber size (Saito et al., 2008).

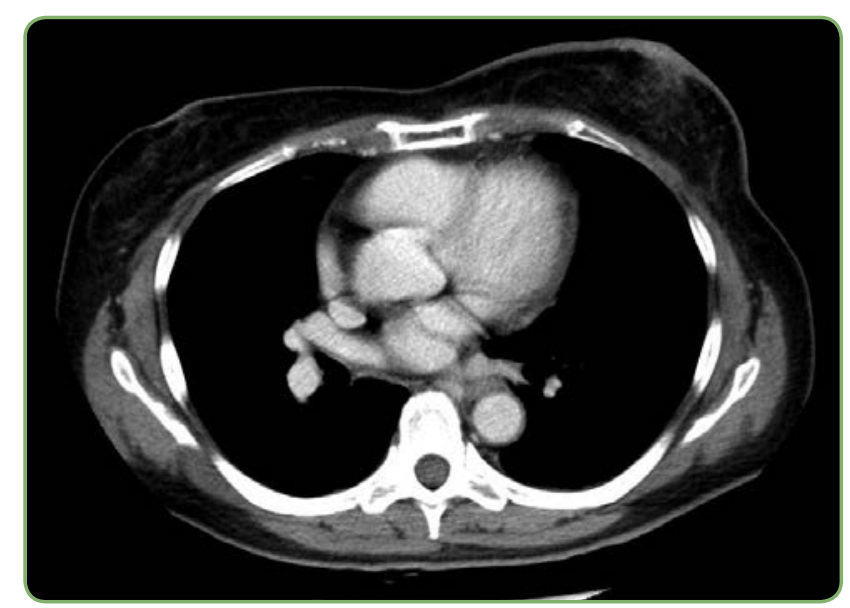

Figure 3. CT thorax done 2 months after pericardiocentesis showing minimal residual pericardial effusion.

Mrs. Y.'s symptoms were typical, as she presented with shortness of breath, the most common symptom, and subsequently developed hypotension. Her rapid improvement with pericardiocentesis is also typical although not universal. Mrs. Y. had multiple risk factors for pericardial effusion, including metastatic breast cancer, history of thoracic radiation, and treatment with cyclophosphamide. Given that these risk factors are present for the majority of patients with metastatic breast cancer, it is important for advanced practitioners to have a high index of suspicion for pericardial effusion in addition to malignant pleural effusion and pulmonary embolus when such patients present with shortness of breath.

\section{CONSIDERATIONS FOR ADVANCED PRACTITIONERS}

Pericardial effusion should be suspected in any patient with a malignancy and any of the following symptoms: dyspnea or pleuritic chest pain, new radiographic cardiomegaly without pulmonary congestion, unexplained persistent fever, presence of an isolated left pleural effusion, or hemodynamic deterioration of unknown etiology (Hoit, 2013b). The most common malignancies causing pericardial effusion are breast and lung cancer, followed by Hodgkin lymphoma, non-Hodgkin lymphoma, and leukemia (Lestuzzi, 2010). Consequently, it is especially important for advanced practitioners to have a high index of suspicion in a patient with one of these malignancies presenting with shortness of breath. 
Radiation-induced pericardial effusion may occur during the radiation therapy itself or up to 20 years after therapy (Lee, Finch, \& Mahmud, 2013), and a history of thoracic radiation therapy should further increase the suspicion of pericardial effusion.

A patient with a moderate pericardial effusion may be minimally symptomatic and may have no specific physical exam findings and a normal ECG. If a pericardial effusion is within the differential diagnosis for the reasons outlined here, echocardiography is the most specific and clinically important diagnostic tool, as it can provide evidence of cardiac compromise prior to the development of overt tamponade. In pericardial effusions that develop slowly and do not cause hemodynamic compromise, systemic chemotherapy is often a better option than invasive intervention. Any patient who develops symptomatic tamponade from a malignant pericardial effusion needs intervention for the effusion, preferably with pericardiocentesis followed by systemic chemotherapy, if these interventions are aligned with the patient's goals of care. For recurrent symptomatic malignant pericardial effusions, a surgical intervention may, after the initial postsurgical recovery period, improve quality of life and reduce hospital stays.

\section{Disclosure}

The author has no potential conflicts of interest to disclose.

\section{References}

Argulian, E., Herzog, E., Halpern, D. G., \& Messerli, F. H. (2012). Paradoxical hypertension with cardiac tamponade. American Journal of Cardiology, 110(7), 1066-1069. http://dx.doi.org/10.1016/j.amjcard.2012.05.042

Bogaert, J., \& Francone, M. (2013). Pericardial disease: Value of CT and MR imaging. Radiology, 267(2), 340-356. http://dx.doi.org/10.1148/radiol.13121059

Borlaug, B. A., DeCamp, M. M., \& Gangadharan, S. P. (2013). Pericardial disease associated with malignancy. In M. M. LeWinter (Ed.), UpToDate. Retrieved from http://www. uptodate.com/home/index.html

Braunwald, E. (2012). Pericardial disease. In D. L. Longo et al. (Eds.), Harrison's principles of internal medicine (18th ed., Vol. 1). New York: McGraw-Hill.

Burazor, I., Imazio, M., Markel, G., \& Adler, Y. (2013). Malignant pericardial effusion. Cardiology, 124(4), 224-232. http://dx.doi.org/10.1159/000348559

Carlson, R. W., Allred, D. C., Anderson, B. O., Burstein, H. J., Carter, W. B., Edge, S. B.,...Wolff, A. C. (2009). Breast cancer. Clinical practice guidelines in oncology. Journal of the National Comprehensive Cancer Network, 7(2), 122-192.

Cham, W. C., Freiman, A. H., Carstens, P. H., \& Chu, F. C. (1975). Radiation therapy of cardiac and pericardial me- tastases. Radiology, 114(3), 701-704.

Cheitlin, M. D., Armstrong, W. F., Aurigemma, G. P., Beller, G. A., Bierman, F. Z., Davis, J. L.,...Russell, R. O. (2003). ACC/ AHA/ASE 2003 guideline update for the clinical application of echocardiography: Summary article. A report of the American College of Cardiology/American Heart Association Task Force on Practice Guidelines (ACC/ AHA/ASE Committee to Update the 1997 Guidelines for the Clinical Application of Echocardiography). Circulation, 108(9), 1146-1162. http://dx.doi.org/10.1161/01. CIR.0000073597.57414.A9

Dequanter, D., Lothaire, P., Berghmans, T., \& Sculier, J. P. (2008). Severe pericardial effusion in patients with concurrent malignancy: A retrospective analysis of prognostic factors influencing survival. Annals of Surgical Oncology, 15(11), 3268-3271. http://dx.doi.org/10.1245/ s10434-008-0059-z

Foulkes, W. D., Smith, I. E., \& Reis-Filho, J. S. (2010). Triplenegative breast cancer. New England Journal of Medicine, 363(20), 1938-1948. http://dx.doi.org/10.1056/NEJMra1001389

Gumrukcuoglu, H. A., Odabasi, D., Akdag, S., \& Ekim, H. (2011). Management of cardiac tamponade: A comparative study between echo-guided pericardiocentesis and surgery-A report of 100 patients. Cardiology Research and Practice, 2011. http://dx.doi.org/10.4061/2011/197838

Heffner, A. C. (2013). Emergency pericardiocentesis. In A. B. Wolfson \& A. M. Stack (Eds.), UpToDate. Retrieved from http://www.uptodate.com/home/index.html

Hellerhoff. (2010). Pericardial effusion in chest x-ray. Wikimedia Commons. Retrieved from http://commons.wikimedia.org/wiki/File:29-01-Perikarderguss_20_Jahre_ Perimyokarditis_pa_Clostridien.png

Hernandez-Aya, L. F., Chavez-Macgregor, M., Lei, X., MericBernstam, F., Buchholz, T. A., Hsu, L.,...Gonzalez-Angulo, A. M. (2011). Nodal status and clinical outcomes in a large cohort of patients with triple-negative breast cancer. Journal of Clinical Oncology, 29(19), 2628-2634. http://dx.doi.org/10.1200/JCO.2010.32.1877

Hoit, B. D. (2011). Pericardial disease. In V. Fuster, R. A. Walsh, \& R. A. Harrington (Eds.), Hurst's the heart (13th ed). New York: McGraw-Hill Professional.

Hoit, B. D. (2013a). Cardiac tamponade. In B. J. Gersh \& J. Hoekstra (Eds.), UpToDate. Retrieved from http://www. uptodate.com/home/index.html

Hoit, B. D. (2013b). Diagnosis and treatment of pericardial effusion. In M. M. LeWinter \& D. J. Sexton (Eds.), UpToDate. Retrieved from http://www.uptodate.com/home/ index.html

Imazio, M., \& Adler, Y. (2013). Management of pericardial effusion. European Heart Journal, 34(16), 1186-1197. http:// dx.doi.org/10.1093/eurheartj/ehs372

Imazio, M., Brucato, A., Barbieri, A., Ferroni, F., Maestroni, S., Ligabue, G.,...Belli, R. (2013). Good prognosis for pericarditis with and without myocardial involvement: Results from a multicenter, prospective cohort study. Circulation, 128(1), 42-49. http://dx.doi.org/10.1161/circulationaha.113.001531

Imazio, M., Spodick, D. H., Brucato, A., Trinchero, R., \& Adler, Y. (2010). Controversial issues in the management of pericardial diseases. Circulation, 121(7), 916-928. http:// dx.doi.org/10.1161/circulationaha.108.844753

Karatolios, K., Pankuweit, S., \& Maisch, B. (2013). Diagnostic 
value of biochemical biomarkers in malignant and nonmalignant pericardial effusion. Heart Failure Reviews, 18(3), 337-344. http://dx.doi.org/10.1007/s10741-012-9327-x

Kim, S. H., Kwak, M. H., Park, S., Kim, H. J., Lee, H. S., Kim, M. S.,...Lee, J. S. (2010). Clinical characteristics of malignant pericardial effusion associated with recurrence and survival. Cancer Research and Treatment, 42(4), 210-216. http://dx.doi.org/10.4143/crt.2010.42.4.210

Kunitoh, H., Tamura, T., Shibata, T., Imai, M., Nishiwaki, Y., Nishio, M.,...Saijo, N. (2009). A randomised trial of intrapericardial bleomycin for malignant pericardial effusion with lung cancer (JCOG9811). British Journal of Cancer, 100(3), 464-469. http://dx.doi.org/10.1038/ sj.bjc. 6604866

Lee, M. S., Finch, W., \& Mahmud, E. (2013). Cardiovascular complications of radiotherapy. American Journal of Cardiology, 112(10), 1688-1696. http://dx.doi.org/10.1016/j. amjcard.2013.07.031

Lestuzzi, C. (2010). Neoplastic pericardial disease: Old and current strategies for diagnosis and management. World Journal of Cardiology, 2(9), 270-279. http://dx.doi. org/10.4330/wjc.v2.i9.270

Lestuzzi, C., Bearz, A., Lafaras, C., Gralec, R., Cervesato, E., Tomkowski, W.,...Imazio, M. (2011). Neoplastic pericardial disease in lung cancer: Impact on outcomes of different treatment strategies. A multicenter study. Lung Cancer, 72(3), 340-347. http://dx.doi.org/10.1016/j.lungcan.2010.10.013

Maisch, B., Ristić, A., \& Pankuweit, S. (2010). Evaluation and management of pericardial effusion in patients with neoplastic disease. Progress in Cardiovascular Diseases, 53(2), 157-163. http://dx.doi.org/10.1016/j.pcad.2010.06.003

Maisch, B., Ristić, A. D., Seferović, P. M., \& Tsang, T. S. M. (2011). Percutaneous balloon pericardiotomy. In Interventional pericardiology (pp. 155-161). New York: Springer.

Maisch, B., Rupp, H., Ristić, A., \& Pankuweit, S. (2013). Pericardioscopy and epi- and pericardial biopsy-A new window to the heart improving etiological diagnoses and permitting targeted intrapericardial therapy. Heart Failure Reviews, 18(3), 317-328. http://dx.doi.org/10.1007/ s10741-013-9382-y

Maisch, B., Seferović, P. M., Ristić, A. D., Erbel, R., Rienmüller, R., Adler, Y.,...Yacoub, M. H. (2004). Guidelines on the diagnosis and management of pericardial diseases executive summary. The Task Force on the Diagnosis and Management of Pericardial Diseases of the European Society of Cardiology. European Heart Journal, 25(7), 587-610. http://dx.doi.org/10.1016/j.ehj.2004.02.002

Mallemat, H. A., \& Tewelde, S. Z. (2013). Pericardiocentesis. In J. R. Roberts \& J. R. Hedges (Eds.), Roberts and Hedges' clinical procedures in emergency medicine (6th ed., pp. 298-318). Philadelphia: Elsevier.

Neragi-Miandoab, S., Linden, P. A., Ducko, C. T., Bueno, R., Richards, W. G., Sugarbaker, D. J.,...Jaklitsch, M. T. (2008). VATS pericardiotomy for patients with known malignancy and pericardial effusion: Survival and prognosis of positive cytology and metastatic involvement of the pericardium: A case control study. International Journal of Surgery, 6(2), 110-114. http://dx.doi.org/10.1016/j. ijsu.2007.12.005
Oliver, C., Marin, F., Pineda, J., Luján, J., Climent, V., García, A.,...Sogorb, F. (2002). Low QRS voltage in cardiac tamponade: A study of 70 cases. International Journal of Cardiology, 83(1), 91-92. http://dx.doi.org/10.1016/S01675273(02)00024-4

Pawlak-Cieślik, A., Szturmowicz, M., Fijałkowska, A., Gątarek, J., Gralec, R., Błasińska-Przerwa, K.,...Tomkowski, W. (2012). Diagnosis of malignant pericarditis: A single centre experience. Kardiologia Polska, 70(11), $1147-1153$.

Refaat, M. M., \& Katz, W. E. (2011). Neoplastic pericardial effusion. Clinical Cardiology, 34(10), 593-598. http:// dx.doi.org/10.1002/clc.20936

Sagristà-Sauleda, J., Angel, J., Sambola, A., \& PermanyerMiralda, G. (2008). Hemodynamic effects of volume expansion in patients with cardiac tamponade. Circulation, 117(12), 1545-1549. http://dx.doi.org/10.1161/circulationaha.107.737841

Sagristà-Sauleda, J., Mercé, A. S., \& Soler-Soler, J. (2011). Diagnosis and management of pericardial effusion. World Journal of Cardiology, 3(5), 135-143. http://dx.doi. org/10.4330/wjc.v3.i5.135

Saito, Y., Donohue, A., Attai, S., Vahdat, A., Brar, R., Handapangoda, I., \& Chandraratna, P. A. (2008). The syndrome of cardiac tamponade with "small" pericardial effusion. Echocardiography, 25(3) 321-327. http://dx.doi. org/10.1111/j.1540-8175.2007.00567.x

Sampat, K., Rossi, A., Garcia-Gutierrez, V., Cortes, J., Pierce, S., Kantarjian, H.,...Garcia-Manero, G. (2010). Characteristics of pericardial effusions in patients with leukemia. Cancer, 116(10), 2366-2371. http://dx.doi.org/10.1002/ cncr.24946

Schoen, F. J., \& Mitchell, R. N. (2010). The heart. In V. Kumar, A. K. Abbas, N. Fausto, \& J. C. Aster (Eds.), Robbins and Cotran pathologic basis of disease (8th ed.). Philadelphia: Saunders.

Seferović, P. M., Ristić, A. D., Maksimović, R., Simeunović, D. S., Milinković, I., Seferović Mitrović, J. P.,...Maisch, B. (2013). Pericardial syndromes: An update after the ESC guidelines 2004. Heart Failure Reviews, 18(3), 255-266. http://dx.doi.org/10.1007/s10741-012-9335-x

Sherbino, J. (2009). Does this patient with a pericardial effusion have cardiac tamponade? Annals of Emergency Medicine, 53(3), 390-391. http://dx.doi.org/10.1016/j. annemergmed.2008.02.015

Svoboda, M. (2010). Malignant pericardial effusion and cardiac tamponade (cardiac and pericardial symptoms). In I. N. Olver (Ed.), The MASCC textbook of cancer supportive care and survivorship (pp. 83-91). New York: Springer.

Tsang, T. S., Enriquez-Sarano, M., Freeman, W. K., Barnes, M. E., Sinak, L. J., Gersh, B. J.,...Seward, J. B. (2002). Consecutive 1127 therapeutic echocardiographically guided pericardiocenteses: Clinical profile, practice patterns, and outcomes spanning 21 years. Mayo Clinic Proceedings, 77(5), 429-436. http://dx.doi.org/10.4065/77.5.429

Uramoto, H., \& Hanagiri, T. (2010). Video-assisted thoracoscopic pericardiectomy for malignant pericardial effusion. Anticancer Research, 30(11), 4691-4694. 